\title{
Treatment of Comminuted Patellar Fractures Using Modified Cerclage Wiring
}

Mohammed Ahmed Shawky, ${ }^{1}$ MSc, Usama Gaber Abd Alla, ${ }^{1}$ MD, Mohammed Mohammed Bissar, ${ }^{1}$ PhD.

* Corresponding Author:

Mohammed Ahmed Shawky

mohammedahmed2shawky@gmail.com Received for publication December 20, 2020; Accepted February 22, 2021; Published online February 22, 2021.

Copyright 2021 The Authors
published by Al-Azhar
University, Faculty of Medicine,
Cairo, Egypt. All rights reserved.
This an open-access article
distributed under the legal terms,
where it is permissible to
download and share the work
provided it is properly cited. The
work cannot be changed in any
way or used commercially.
doi: $10.21608 /$ aimj.2021.54343.1377.
${ }^{1}$ Orthopedic Surgery Department,
Faculty of Medicine, Al-Azhar
University.

University.

\begin{abstract}
Background: Comminuted patellar fracture is still challenging. It is essential to restore the articular cartilage with rigid internal fixation.

Aim of the study: was to assess the outcome of modified cerclage wiring fixation in patients with comminuted patellar fracture.

Patients and Methods: This study was done in orthopedic surgery department at Al-Azhar University Hospitals, during the period from December 2019 to November 2020. A total of 15 patients with comminuted fracture of patella were maneged by modified cerclage wiring. 12 patients were males $(80.0 \%)$ and 3 patients were females (20.0\%). Their age was $18-64$ (average $38.87 \pm 14.80$ ) years. All patients had unilateral patellar fractures. The fractures were closed in 12 patients $(80.0 \%)$ and open in 3 patients $(20.0 \%)$. We followed up our patients for at least 6 months. Böstman grading score was the main clinical outcome indicator.

Results: The fracture union occurred radiologically about 2-3.5 months (mean 2.70 \pm 0.46 months). 2 cases had self-limited postoperative superficial infection. No postoperative complications such as fragment re-displacement, implants breakage, , painful hardware and non-union were observed. Clinical outcomes according to grading score of Böstman were satisfactory and the average score was 28.13 \pm 1.73 (range 24-30) points. 12 patients had excellent results with an average score of $28.8 \pm$ 0.71 (range 28-30) points and 3 patients had good results with an average score of $25.33 \pm 1.53$ (range 24-27) points. All patients had knee flexion 110-140 (mean 127.33 \pm 9.61 ) degrees.

Conclusion: Modified cerclage wiring fixation offers a new technique in comminuted patellar fracture treatment with satisfactory results and minimal complications.
\end{abstract}

Keywords: comminuted patellar fracture, double cerclage.

Disclosure: The authors have no financial interest to declare in relation to the content of this article. The Article Processing Charge was paid for by the authors.

Authorship: All authors have a substantial contribution to the article.

\section{INTRODUCTION}

Patellar fractures account for about $1 \%$ of fractures in adults. ${ }^{1}$ Comminuted patellar fractures account $55 \%$ of the surgically treated patellar fracture. ${ }^{2}$ Surgical treatment is indicated for disruption of extensor mechanism, articular step-off more than 2-3 mm, and displacement more than $4 \mathrm{~mm}^{1}$ The management of comminuted fractures in patella is still a challenge to surgeons. ${ }^{3}$ The targets of surgical management for patellar fractures include restoring the extensor apparatus, restoring the articular cartilage congruity, decreasing patellar bone loss and promoting early range of knee flexion. Nowadays, numerous surgical procedures of patellar comminuted fractures management are available, including circumferential cerclage fixation, ${ }^{2}$ modified tension band fixation, ${ }^{4}$ nickel-titanium patella concentrator, ${ }^{5}$ cable-pin system, ${ }^{6}$ titanium cable cerclage, ${ }^{7}$ fixation by plating and screws ${ }^{8}$ and patellectomy either partial or total. ${ }^{9}$
Using ORIF is the best choice in comminuted patellar fractures because it facilitates stable fixation to the fragments that promotes early range of movement. ${ }^{10}$ Combination of different methods of fixation were described to treat comminuted fractures of patella, such as combining modified tension band with circumferential cerclage fixation, ${ }^{11}$ combining nickel-titanium patellar concentrator with nonabsorbable suture cerclage $\mathrm{e}^{12}$ and combining headless compression screws with wiring. ${ }^{13}$

We present a different technique in the surgical management of comminuted fractures in patella by using modified cerclage fixation (double cerclage).

\section{PATIENTS AND METHODS}

This prospective cohort study was done in orthopedic surgery department at Al-Azhar University Hospitals, 
during the period from December 2019 to November 2020. All procedures followed Al-Azhar University ethical committee regulations, and all patients gave written consents. No financial support. A total of 15 patients presented by comminuted fractures of patella were treated by modified cerclage wire fixation. 12 patients were males $(80.0 \%)$ and 3 patients were females (20.0\%) and their age was ranging 18-64 (average $38.87 \pm 14.80$ ). All patients had unilateral patellar fracture, 10 patients had fracture of right patella (66.7\%) and 5 patients had fracture of left patella (33.3\%). The fractures were closed in 12 patients (80.0\%) and open in 3 patients (20.0\%). In the mechanism of fracture, 7 cases (46.7\%) had the fracture from traffic accidents and 8 cases (53.3\%) had the fracture from falls. The time from the trauma to surgery was $1-10$ days (average $2.87 \pm 2.36$ days).

Inclusion criteria: Comminuted patellar fractures more than 2 fragments. Patients aging between 15 and 70 years.

Exclusion criteria: Simple patellar fractures (2 fragments). Patients less than 15 years old and more than 70 years old. Patients unfit for surgery.

We subjected all our patients to full history taking, complete general and local clinical examination, affected patella anteroposterior and lateral radiographs, first aid fracture management and complete preoperative work up. Polytrauma patients had initial first aid management according to ATLS protocol. Patients with open fractures were initially managed by intravenous prophylactic antibiotics and wound irrigation and debridement with removal of gross contamination and necrotic tissues.

Surgical procedures: Surgery was performed under general or spinal anesthesia. Our patients laid supine and the affected knee was extended. Above knee tourniquet was inflated. We made an anterior midline incision of the skin of the knee followed by dissection of superficial fascia. We examined the integrity of the extensor mechanism. The fracture patella was exposed and the fracture hematoma was cleaned. We reduced the fracture using the fracture reduction clamp and fixation of the fragments was done temporarily with Kirschner wires. We checked the articular surface by an x-ray fluoroscopy to ensure the articular surface congruity. We sutured the first wire around the upper half of the patella intermittently, reserving parts of the wire to form 2 loops. We sutured the second wire around the lower half of the patella intermittently, and parts of the wire were reserved to form another 2 loops. We used a third wire to pass through the reserved loops superficial to the patella and tightened it to the loops. Then, two surgeons tightened the first and second wires at the same time to an appropriate degree without over tightening. We checked the articular congruity again by $x$-ray fluoroscopy. The ends of the wires were cut and buried properly to avoid postoperative hardware irritation. Finally, we sutured the anterior patellar ligament and the wound was closed. The time of surgery was $60-90 \min (72.7 \pm$ 9.1min) (Figur 1).

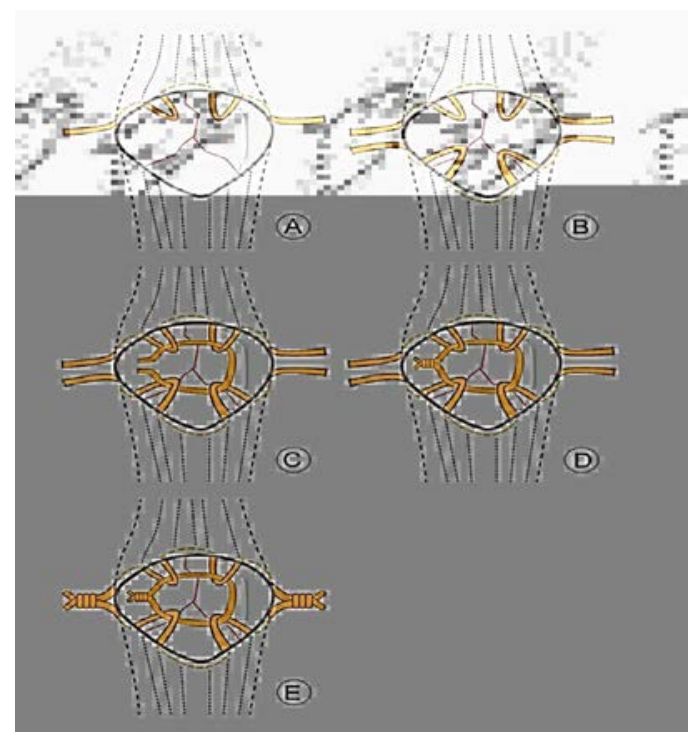

Fig 1: Illustration of the surgical procedures.

Postoperative management: Posterior slab was applied for 1-2 weeks to decrease postoperative pain. Functional exercises were started after slab removal. We encouraged our patients to start partial weightbearing in extension once the postoperative pain was tolerated. We followed up all our patients for at least 6 months and postoperative outcomes and complications were assessed clinically and radiologically. Patients were followed up every 2-4 weeks at the first 3 months, and every 1.5 months after that. Anteroposterior and lateral patellar radiographs were obtained 1day, 4weeks, 8weeks and 12 weeks after surgery and every 3 months after that. The criteria that indicate union include weight bearing without help, the absence of tenderness and the presence of bone trabeculae of the line of fracture at plain radiographs. We used Böstman score in the clinical assessment of our postoperative results which include range of motion, pain, assistance in walking, work, effusion, atrophy, giving way and stairclimbing. 28-30 points are considered excellent, 2027 points are considered good and less than 20 points are considered unsatisfactory ${ }^{3}$ (Figur 2, 3, 4).

\section{Statistical analysis}

Our results were evaluated by Independent t-test, Chi-square test and ANOVA test. $\mathrm{P}$ value less than 0.05 was considered statistically significant.

\section{RESULTS}

A total of 15 patients were followed up for at least 6months. The time from surgery to fracture union was about 2-3.5 months (mean $2.70 \pm 0.46$ months). There were no complications, such as nonunion, loosening of internal fixation, re-displacement, breakage of fixation and. 2 cases had postoperative self limited infection and subsided by antibiotics. The average score Böstman score was $28.13 \pm 1.73$ 
(ranging 24-30) points. 12 patients (80.0\%) had excellent results with average score $28.8 \pm 0.71$ (ranging 28-30) points and 3 patients (20.0\%) had good results with average score $25.33 \pm 1.53$ (ranging 24-27) points. No patients had unsatisfactory results. (Table 1).
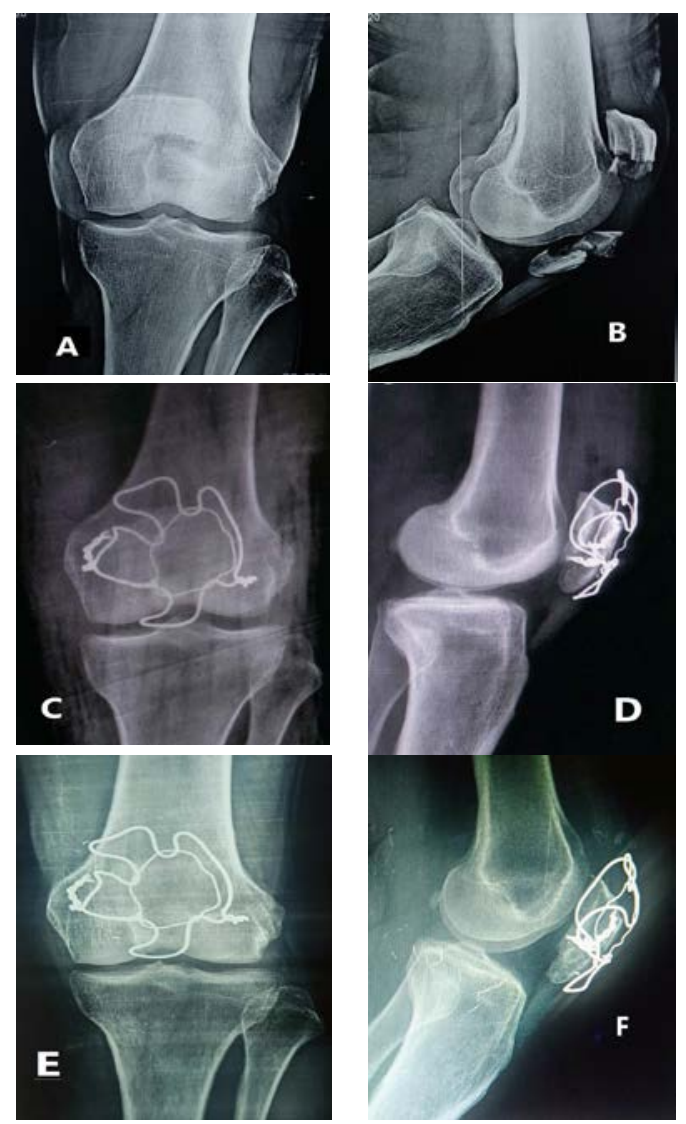

Fig 2: (A and B) Preoperative $x$-rays of comminuted fracture patella. $(C$ and $D)$ postoperative $x$-rays of comminuted fracture patella. (E and F) Follow up Xrays of comminuted fracture patella 3 months after the operation.

All patients had knee flexion 110-140 (average $127.33 \pm 9.61$ ) degrees at final follow up (Table 2). Patients with excellent results had average knee flexion 120-140 (average130.00 \pm 8.53) degrees while patients with good results had average knee flexion 110-120 (average $116.67 \pm 5.77$ ). There was a significant correlation between the range of knee flexion and Böstman score at final follow up (Table $3)$.

While there were no statistically significant differences between males and females, there was statistically significant correlation according to age. Patients with excellent results had average age 34.42 \pm 12.52 (range $18-55$ ) years and patients with good results had average age $56.67 \pm 8.74$ (range $47-64$ ) years (Table 4).

There were no statistically significant differences between open and closed fractures or as regard the mode of trauma (Table 5).

There was no statistically significant correlation regarding the interval between the injury and the operation within the study cases (Table 6).

Two patients had associated fractures; the first had ipsilateral distal radius (DR) fracture, treated with percutaneous pinning by Kirschner wires (K-wires) and healed within 8 weeks with no significant correlation to the results (Table 7). The other, had ipsilateral old united shaft femur and shaft tibia fractures, treated by ilizarov fixators 3 years before the injury and there was significant correlation to the final score and range of knee flexion which might be contributed to the initial injury (Table 7).

\begin{tabular}{|c|c|c|}
\hline \multicolumn{2}{|c|}{} & No. $=15$ \\
\hline \multirow{2}{*}{ Böstman score } & Mean \pm SD & $28.13 \pm 1.73$ \\
\cline { 2 - 3 } & Range & $24-30$ \\
\hline \multirow{4}{*}{ Böstman score } & Good & $\mathbf{3 ( 2 0 . 0 \% )}$ \\
& Mean \pm SD & $25.33 \pm 1.53$ \\
& Range & $24-27$ \\
\cline { 2 - 3 } & Excellent & $\mathbf{1 2}(\mathbf{8 0 . 0} \%)$ \\
& Mean \pm SD & $28.80 \pm 0.71$ \\
& Range & $28-30$ \\
\hline
\end{tabular}

Table 1: The results according to Böstman score.

\begin{tabular}{|l|c|c|}
\hline \multicolumn{2}{|c|}{} & No. $=15$ \\
\hline \multirow{2}{*}{ Knee flexion at 6ws } & Mean \pm SD & $81.33 \pm 18.07$ \\
\cline { 2 - 3 } & Range & $50-110$ \\
\hline \multirow{2}{*}{ Knee flexion at 12ws } & Mean \pm SD & $111.33 \pm 14.07$ \\
\cline { 2 - 3 } & Range & $90-140$ \\
\hline \multirow{2}{*}{ Knee flexion at 24ws } & Mean \pm SD & $127.33 \pm 9.61$ \\
\cline { 2 - 3 } & Range & $110-140$ \\
\hline
\end{tabular}

Table 2: Average knee flexion follow up.

Table 2:

\begin{tabular}{|c|c|c|c|c|c|c|}
\hline & \multicolumn{2}{|c|}{ Böstman score } & \multirow{3}{*}{ Test value } & \multirow{3}{*}{ P-value } & \multirow{3}{*}{ Sig. } \\
\hline & & Good & Excellent & & & \\
\hline & & No. $=3$ & No. $=12$ & & & \\
\hline Kno flovion at 6 we & Mean \pm SD & $60.00 \pm 17.32$ & $86.67 \pm 14.35$ & 2782 & 0016 & $\mathrm{~S}$ \\
\hline Nite nexion do ows & Range & $50-80$ & $70-110$ & -2.102 & 0.010 & 0 \\
\hline Knoe flexion at 12wc & Mean \pm SD & $100.00 \pm 10.00$ & $114.17 \pm 13.79$ & -1653 & 0122 & NS \\
\hline Nive Hexion ad $12 \mathrm{ws}$ & Range & $90-110$ & $90-140$ & -1.030 & 0.122 & 105 \\
\hline & Mean \pm SD & $116.67 \pm 5.77$ & $130.00 \pm 8.53$ & & & \\
\hline Knee flexion at $24 w s$ & Range & $110-120$ & $120-140$ & -2.530 & 0.025 & $\mathrm{~s}$ \\
\hline
\end{tabular}

Table 3: Comparison between the knee flexion of patients with good and excellent score. 


\begin{tabular}{|c|c|c|c|c|c|c|}
\hline & \multicolumn{2}{|c|}{ Böstman score } & \multirow{2}{*}{ Test value } & \multirow{2}{*}{ P-value } & \multirow{2}{*}{ Sig. } \\
\hline & & Mean \pm SD & Range & & & \\
\hline \multirow{3}{*}{ Age } & Age $<35$ & $29.50 \pm 0.55$ & $29-30$ & \multirow{3}{*}{5.557} & \multirow{3}{*}{0.020} & \multirow{3}{*}{ S } \\
\hline & Age (35 - 54) & $27.50 \pm 1.76$ & $24-29$ & & & \\
\hline & Age $>=55$ & $26.67 \pm 1.53$ & $25-28$ & & & \\
\hline \multirow{2}{*}{ Gender } & Female & $28.33 \pm 0.58$ & $28-29$ & \multirow{2}{*}{0.217} & \multirow{2}{*}{0.832} & \multirow{2}{*}{ NS } \\
\hline & Male & $28.08 \pm 1.93$ & $24-30$ & & & \\
\hline & & \multicolumn{2}{|c|}{ Böstman score } & \multirow{3}{*}{ Test value } & \multirow{3}{*}{ P-value } & \multirow{3}{*}{ Sig. } \\
\hline & & Good & Excellent & & & \\
\hline & & No. $=3$ & No. $=12$ & & & \\
\hline \multirow{2}{*}{ Age } & Mean \pm SD & $56.67 \pm 8.74$ & $34.42 \pm 12.52$ & \multirow{2}{*}{2.868} & \multirow{2}{*}{0.013} & \multirow{2}{*}{$\mathbf{S}$} \\
\hline & Range & $47-64$ & $18-55$ & & & \\
\hline \multirow{2}{*}{ Gender } & Female & $0(0.0 \%)$ & $3(25.0 \%)$ & \multirow{2}{*}{0.938} & \multirow{2}{*}{0.333} & \multirow{2}{*}{ NS } \\
\hline & Male & $3(100.0 \%)$ & $9(75.0 \%)$ & & & \\
\hline
\end{tabular}

Table 4: Statistical differences according to age and sex.

\begin{tabular}{|c|c|c|c|c|c|c|c|c|}
\hline & & \multicolumn{4}{|c|}{ Böstman score } & \multirow{2}{*}{ Test value } & \multirow{2}{*}{ P-value } & \multirow{2}{*}{ Sig. } \\
\hline & & \multicolumn{2}{|c|}{ Mean \pm SD } & & & & \\
\hline \multirow{2}{*}{ closed/open } & Close & \multicolumn{2}{|c|}{$28.33 \pm 1.37$} & & $25-30$ & \multirow{2}{*}{0.891} & \multirow{2}{*}{0.389} & \multirow{2}{*}{ NS } \\
\hline & Open & \multicolumn{2}{|c|}{$27.33 \pm 3.06$} & \multicolumn{2}{|r|}{$24-30$} & & & \\
\hline \multirow{2}{*}{$\begin{array}{c}\text { Mode of } \\
\text { trauma }\end{array}$} & Fall & \multirow{2}{*}{\multicolumn{2}{|c|}{$\begin{array}{l}27.88 \pm 1.36 \\
28.43 \pm 2.15\end{array}$}} & \multirow{2}{*}{\multicolumn{2}{|c|}{\begin{tabular}{|l|}
$25-29$ \\
$24-30$
\end{tabular}}} & \multirow{2}{*}{-0.605} & \multirow{2}{*}{0.555} & \multirow{2}{*}{ NS } \\
\hline & Traffic accident & & & & & & & \\
\hline & & \multicolumn{4}{|c|}{$\begin{array}{l}\text { Böstman score } \\
\end{array}$} & \multirow{3}{*}{ Test value } & \multirow{3}{*}{ P-value } & \multirow{3}{*}{ Sig. } \\
\hline & & \multicolumn{2}{|c|}{ Good } & \multicolumn{2}{|c|}{ Excellent } & & & \\
\hline & & No. & $\%$ & No. & $\%$ & & & \\
\hline \multirow{2}{*}{ Closed/open } & Close & 2 & $66.7 \%$ & 10 & $83.3 \%$ & \multirow{2}{*}{0.417} & \multirow{2}{*}{0.519} & \multirow{2}{*}{ NS } \\
\hline & Open & 1 & $33.3 \%$ & 2 & $16.7 \%$ & & & \\
\hline \multirow{2}{*}{$\begin{array}{l}\text { Mode of } \\
\text { trauma }\end{array}$} & Fall & 2 & $66.7 \%$ & 6 & $50.0 \%$ & \multirow{2}{*}{0.268} & \multirow{2}{*}{0.605} & \multirow{2}{*}{ NS } \\
\hline & Traffic accident & 1 & $33.3 \%$ & 6 & $50.0 \%$ & & & \\
\hline
\end{tabular}

Table 5: Statistical differences between open and closed fractures and according to mode of injury

\begin{tabular}{|c|c|c|c|c|c|c|}
\hline & & & \multicolumn{4}{|c|}{ No. $=15$} \\
\hline \multirow{2}{*}{\multicolumn{2}{|c|}{ Interval before operation. (days) }} & Mean \pm SD & \multicolumn{4}{|c|}{$2.87 \pm 2.36$} \\
\hline & & Range & \multicolumn{4}{|c|}{$1-10$} \\
\hline & & \multicolumn{2}{|c|}{ Böstman score } & \multirow{3}{*}{ Test value } & \multirow{3}{*}{ P-value } & \multirow{3}{*}{ Sig. } \\
\hline & & Good & Excellent & & & \\
\hline & & No. $=3$ & No. $=12$ & & & \\
\hline \multirow{2}{*}{ Interval before operation (days) } & Mean \pm SD & $2.33 \pm 0.58$ & $3.00 \pm 2.63$ & \multirow{2}{*}{-0.425} & \multirow{2}{*}{0.678} & \multirow{2}{*}{ NS } \\
\hline & Range & $2-3$ & $1-10$ & & & \\
\hline
\end{tabular}

Table 6: Statistical differences according to the time between the injury and the operation.

\begin{tabular}{|c|c|c|c|c|}
\hline & $\begin{array}{c}\text { Knee flexion } \\
\text { at 6 weeks }\end{array}$ & $\begin{array}{c}\text { Knee } \\
\text { flexion at 12 } \\
\text { weeks }\end{array}$ & $\begin{array}{c}\text { Knee flexion } \\
\text { at 24 weeks }\end{array}$ & $\begin{array}{c}\text { Böstman score } \\
\text { at } \mathbf{6} \text { months }\end{array}$ \\
\hline Ipsilateral DR fracture & $0-80$ & $0-110$ & $0-120$ & 28 \\
\hline Ipsilateral shaft femur and tibia fractures & $0-50$ & $0-100$ & $0-110$ & 24 \\
\hline
\end{tabular}

Table 7: Results of the patients with associated fractures.

\section{DISCUSSION}

Displaced comminuted patellar fractures require surgical treatment. ${ }^{2}$ Several methods have been described in surgical management of comminuted fractures of patella. ${ }^{3}$ In our study of 15 cases of comminuted patellar fractures treated by modified cerclage wire fixation, all patients (100\%) had excellent (80\%) and good (20\%) results with a $100 \%$ union rate range $2-3.5$ (average $2.70 \pm 0.46$ ) months. All patient had full knee extension and average knee flexion $127.33 \pm$ 9.61(range 110 - 140) degrees.

Tension band fixation according to AO principles is the most famous technique used in the treatment for simple patellar fractures without significant comminution. ${ }^{14}$ Treatment of comminuted fractures of patella alone with this method is difficult. For comminuted patellar fractures, satisfactory results can be achieved by adding inter-fragmentary screws 
or cerclage wires to tension band fixation. Hambright et al. ${ }^{15}$ added an enhancement to the usual tension band at which they added more wires and tension bands in management of comminuted fractures of patella. The wires and tension bands they added may cause damage to the soft tissue around the fracture and cause complications such as pain from hardware, broken K-wires and prominent hardware.

The stability of cerclage wire fixation was significantly worse than that of tension band. ${ }^{16}$ The fixation was not strong enough to withstand the contraction power of quadriceps muscle and the knee flexion. During rehabilitation, there were some problems such as loosening and breaking of internal fixation leading to re-displacement of the fracture fragments, failure of internal fixation and injury of the articular surface so the patients could not achieve early exercise. Early complications, such as atrophy of quadriceps femoris muscle and knee joint stiffness, may be the cause of bad long term outcome of joint function. ${ }^{2}$ Cerclage wiring fixation is used as an adjunct with other fixation measures. ${ }^{11}$

Matsuo et al. ${ }^{17}$ combined soft tissues with cerclage in the treatment of patellar comminuted fractures.they reported a union rate of $80 \%$.

Yang et al. ${ }^{18}$ used a titanium cable cerclage method in the treatment of patellar comminuted fractures. They reported union rate of $100 \%$ with $100 \%$ excellent and good results.

Lue et al. ${ }^{12}$ used non-absorbable suture cerclage combined with nickel-titanium patellar concentrator in fixing patellar comminuted fractures. They reported that $76.1 \%$ of their patients had excellent scores and $23.9 \%$ had good scores. In comminuted patellar fractures, stable fixation of laterally displaced fragments cannot be achieved because knee joint flexion lead to traction on the patello-femoral constructs.

Wurm et al. ${ }^{8}$ used angular stable patella plate in patellar fracture treatment and reported that the rate of their complication was apout $7 \%$. There were no extension lag. The average knee flexion was 128 degrees. Taylor et al. ${ }^{19}$ used plating in treatement of patellar fractures and non-unions and they supplemented the plating py inter-fragmentary screws.They reported an average union time of 3.1 months with the range of knee joint flexion of 130 degrees. There were no cases of painful hardware.

Wu et al. ${ }^{20}$ reported range of knee flexion of 138.9 (110-140) degrees after using tension band wiring . Chang et al. ${ }^{21}$ used modification of tension band wiring with cannulated screws and reported a knee flexion of 124 (100-140) degrees. In our study using modified cerclage wire fixation, the mean knee flexion was 127.33 (110-140) degrees, which was similar to the range of motion they reported.

In our study, the average time for union of fractures after fixation was $2.70 \pm 0.46$ months, which is comparable to the average time of union of 2.82 months reported by Lue et al. ${ }^{12}$

Our study suggests that this new strategy can give comparable clinical outcomes in comminuted patellar fracture treatment with satisfactory results and minimal complications.

\section{CONCLUSION}

The combination of IPACK block with ACB has the potential of being an adequate technique for management of acute postoperative pain after TKA but this needs more researches of larger samples and use of other types of local anesthetics with different volumes and concentrations.

\section{REFERENCES}

1. Barrington JW, Halaszynski TM, and Sinatra RS. Perioperative pain management in hip and knee replacement surgery. Am J Orthop. 2014; 43 (4): 1-16.

2. Seo SS, Kim OG, Seo JH, et al. Comparison of the effect of continuous femoral nerve block and adductor canal block after primary total knee arthroplasty. Clin Orthop Surg. 2017; 9: 303-9.

3. Li JW, Ma YS, and Xiao LK. Postoperative Pain Management in Total Knee Arthroplasty. Orthop Surg. 2019; 11 (5): 755-61.

4. Memtsoudis SG, Yoo D, Stundner O, et al. Subsartorial adductor canal vs. femoral nerve block for analgesia after total knee replacement. Int Orthop. 2015; 39: $673 \quad-80$.

5. Gao F, Ma J, Sun W, et al. Adductor canal block versus femoral nerve block for analgesia after total knee arthroplasty: A systematic review and meta Edmalysisin. 2017; 33: $356-68$.

6. Yadeau JT, Goytizolo EA, Padgett DE, et al. Analgesia after total knee replacement: local infiltration versus epidural combined with a femoral nerve blockade: a prospective, randomized pragmatic trial. Bone Joint J. 2013; 95-B (5): 629-35.

7. Baratta JL, Gandhi K, and Viscusi ER. Perioperative pain management for total knee arthroplasty. J Surg Orthop Adv. 2014; 23 (1): 22-36.

8. Thobhani S, Scalercio L, Elliott CE, et al. Novel Regional Techniques for Total Knee Arthroplasty Promote Reduced Hospital Length of Stay: An Analysis of 106 Patients. Ochsner J. 2017; 17 (3): 233-8.

9. Subramanian B, Shastri N, Aziz L, et al. ASSIST - Patient satisfaction survey in postoperative pain management from Indian subcontinent. Journal of Anaesthesiology Clinical Pharmacology. 2017; 33 (1): 40-7.

10. Sankineani SR, Reddy ARC, Eachempati KK, et al. Comparison of adductor canal block and IPACK block (interspace between the popliteal artery and the capsule of the posterior knee) with adductor canal block alone after total knee arthroplasty: a prospective control trial on pain and knee function in immediate postoperative 
period. Eur J Orthop Surg Traumatol. 2018; 28(7): 1391-5.

11. Cong Z, Zhang L, and Ma F. The efficacy and safety of the infiltration of the interspace between the popliteal artery and the capsule of the knee block in total knee arthroplasty: A prospective randomized trial protocol. Medicine (Baltimore). 2020; 99 (33): 21670.

12. Surjya Prasad U, Sudhakar T, Sunil K, et al. Postoperative Analgesia in Total Knee Arthroplasty (TKA) - The Changing Trends. Biomed J Sci \& Tech Res. 2017; 1(3): 713-9.

13. El-Emam EM and Abd El motlb EA. UltrasoundGuided Adductor Canal Block versus Combined Adductor Canal and Infiltration between the Popliteal Artery and the Posterior Capsule of the Knee Block for Osteoarthritis Knee Pain. Anesthesia: Essays and Researches. 2020; 14(1): 127-31.

14. Abdallah FW, Madjdpour C, and Brull R. Is sciatic nerve block advantageous when combined with femoral nerve block for postoperative analgesia following total knee arthroplasty? A meta-analysis. Can J Anaesth. 2016; 63 (5): 55268.

15. Eldegwy HM and Negm MA. Adductor Canal Block Combined with Sciatic Nerve Block Vs. Local Analgesic Infiltration for Pain Control after Total Knee Arthroplasty. J Anesth Clin Res. 2018; 9: 799-805.

16. Sinha SK, Abrams JH, Arumugam S, et al. Femoral nerve block with selective tibial nerve block provides effective analgesia without foot drop after total knee arthroplasty: a prospective, randomized, observer-blinded study. Anesth Analg. 2012; 115 (1): 202-6.

17. Caballero-Lozada AF, Gomez JM, Ramírez JA, et al. IPACK block: emerging complementary analgesic technique for total knee arthroplasty. Colombian Journal of Anesthesiology. 2020; 48 (2): 78-84.

18. Patterson ME, Vitter J, Bland K, et al. The Effect of the IPACK Block on Pain After Primary TKA: A Double-Blinded, Prospective, Randomized Trial. The Journal of Arthroplasty. 2020; 35 (6): 1-5. 